\title{
Physical Activity, Screen Time and Sleep among Youth Participating and Non-Participating in Organized Sports-The Finnish Health Promoting Sports Club (FHPSC) Study
}

\author{
Kasper Mäkelä1, Sami Kokko ${ }^{*}$, Lasse Kannas ${ }^{1}$, Jari Villberg' ${ }^{1}$, Tommi Vasankari² ${ }^{2}$ J. Olli Heinonen ${ }^{3}$, \\ Kai Savonen4, Lauri Alanko5, Raija Korpelainen6,7,8, Harri Selänne9, Jari Parkkari10
}

\author{
${ }^{1}$ Department of Health Sciences, University of Jyväskylä, Jyväskylä, Finland \\ ${ }^{2}$ UKK Institute of Health Promotion Research, Tampere, Finland \\ ${ }^{3}$ Paavo Nurmi Centre and Department of Physical Activity \& Health, University of Turku, Turku, Finland \\ ${ }^{4}$ Kuopio Research Institute of Exercise Medicine, Kuopio, Finland \\ ${ }^{5}$ Clinic of Sports and Exercise Medicine, Foundation for Sport and Exercise Medicine, Helsinki, Finland \\ ${ }^{6}$ Department of Sports and Exercise Medicine, Oulu Deaconess Institute, Oulu, Finland \\ ${ }^{7}$ Center of Life Course Health Research, University of Oulu, Oulu, Finland \\ ${ }^{8}$ Medical Research Center, University of Oulu and University Hospital of Oulu, Oulu, Finland \\ ${ }^{9}$ LIKES Foundation for Sport and Health Sciences and Mehiläinen Sports Clinic, Jyväskylä, Finland \\ ${ }^{10}$ Tampere Research Center of Sports Medicine, Tampere, Finland \\ Email: *sami.p.kokko@jyu.fi
}

How to cite this paper: Mäkelä, K. et al. (2016). Physical Activity, Screen Time and Sleep among Youth Participating and NonParticipating in Organized Sports-The Finnish Health Promoting Sports Club (FHPSC) Study. Advances in Physical Education, 6, 378-388.

http://dx.doi.org/10.4236/ape.2016.64038

Received: September 14, 2016

Accepted: November 3, 2016

Published: November 7, 2016

Copyright $\odot 2016$ by authors and Scientific Research Publishing Inc. This work is licensed under the Creative Commons Attribution International License (CC BY 4.0).

http://creativecommons.org/licenses/by/4.0/

\begin{abstract}
Objectives: The aim of this Health Promoting Sport Club (HPSC) study was to compare physical activity (PA), sleep time and screen time (ST) between sports club participants $(n=1200)$ and non-participants $(n=913)$. Design: A cross-sectional survey design was employed to assess PA, sleep and ST of adolescents. Methods: Information on these was collected from 14 to 16 year old adolescents (1200 sport club participants and 913 non-participants) through a standardized questionnaire. Results: Boys were more physically active than girls and met the PA guidelines more often than girls $(p<0.001)$. The proportion of youth reaching the PA guidelines was significantly higher among youth participants in organized sports $(24.3 \%)$ compared to non-participants $(14.5 \%)(p<0.001)$. Sport club participants slept longer $(1.25$ hours) during weekends than non-participants $(p<0.001)$. Girls reported less ST than $(30$ minutes) boys $(p<0.001)$. Sport club participants reported less ST than non-participants $(0.5$ hours) $(p<0.001)$. Conclusions: Youth participating in organized sports met the recommendations for PA, ST and sleep more often than nonparticipants, supporting sports clubs' contribution to health promotion. At the same
\end{abstract}


time, only minor portion of sporting youth met the recommendations, therefore more attention should be focused on sport club participants' PA, sleep and ST especially in coaching.

\section{Keywords}

Sport Club Participation, Physical Activity, Sleep, Screen Time, Adolescents, Health Promotion

\section{Introduction}

There are evidence based recommendations for physical activity (PA), sleep and screen time (ST) for children and adolescent (National Sleep Foundation, 2006; Strasburger \& Hogan, 2013; WHO, 2013). Global recommendation of PA for health is stated to consist of 60 minutes of daily moderate to vigorous physical activity (MVPA). In addition, the recommendation states that vigorous intensity physical activity (VPA) should be incorporated at least three times a week (WHO, 2013). A study from 32 countries in North America and Europe revealed that $23.1 \%$ of boys and $14.0 \%$ of girls at age of 13 15 met the MVPA recommendation in 2010 (Kalman et al., 2015). However, the proportion of boys that met the MVPA guidelines varied from $10.7 \%$ to $34.3 \%$ in different countries. Respectively, among girls the variation was, 5.4\% - 22.0\%. In Finland, 29.7\% of 13 to 15 years old boys and $17.7 \%$ of same age girls met the guidelines for MVPA in 2010 (Kalman et al., 2015). The proportion of those that met the guidelines tends to decrease over age. This is especially true in Finland, where only $10.0 \%$ of girls and $17.0 \%$ of boys meet the guidelines at the age of 15 (Aira, Kannas, Tynjälä, Villberg, \& Kokko, 2013).

Young sports club participants have higher levels of MVPA than non-participants (Taliaferro, Rienzo, \& Donovan, 2010). However, quite recently it has been found, that among sport club participants in the Nordic countries (Hakkarainen et al., 2008), a third of youth do not meet the MVPA recommendations. Among sports participants, boys are more likely to reach the MVPA guidelines (Silva, Andersen, Aires, Mota, Oliveira, \& Ribeiro, 2013) they have more VPA and they are more likely to be fit than girls (Kin-Isler, Asci, Altins, \& Guven-Karahan, 2009).

Sufficient amount of sleep is fundamental to growth and development as well as recovering from daily activities. Optimal sleep duration among adolescent is recommended to be nine hours or more (Strasburger \& Hogan, 2013). Nearly 70\% of adolescents in 9 different countries had daily sleep duration at least eight hours, which still is short of the recommendation (Garaulet et al., 2011). In Finland, boys are sleeping longer than girls (Nuutinen et al., 2014). Sport participants have better sleep patterns (e.g. better sleep quality, lower number of awakenings), less tiredness and higher concentration during the day than their non-participant peers (Brand, Gerber, Beck, Hatzinger, Pühse, \& Holsboer-Trachsler, 2010). Some studies have not found differences between sports participants and non-participants (Singh \& Baig, 2014) or association 
between PA (not sports participation) and sleep has only been found among girls (Tynjälä, Kannas, Levälahti, \& Välimaa, 1999).

International recommendation for daily ST for children is a maximum of two hours (Strasburger \& Hogan, 2013). A high amount of ST is associated with poorer physical health, reduction of life-satisfaction (Iannotti, Kogan, Janssen, \& Boyce, 2009), lower self-esteem, and reduced psychological well-being (Page, Cooper, Griew, \& Jago, 2010). In Finland $78.0 \%$ of youth exceed these recommendations (Gråsten, Liukkonen, Jaakkola, \& Tammelin 2014). Generally, boys spend more time with video games and computers than girls (Thibault, Contrand, Saubusse, Baine, \& Maurice-Tison, 2010).

Higher level of PA does not necessarily indicate lower level of ST. Comparisons between 32 countries revealed that ST was not associated with the amount of MVPA (Borraccino et al., 2009). There are different kinds of groups; some may be physically active, but still have a lots of ST and others may be physically less active, but still have small amounts of ST. Similar results have been reported also in other studies (Karaca, Caglar, Bilgilli, \& Ayez, 2011; Pyky et al., 2015). Interestingly, sport participants who engage to multiple sports, meet the MVPA, VPA and ST recommendations better than those who participate only in one sport (Sirard, Pfeiffer, Dowda, \& Pate, 2008).

Participation to organized sport is central content of life for those who participate, but they also attend to school many hours in a week. Education-related factors have been identified to be in association with health habits. For example, good academic achievement has been found to be associated with higher level of PA and lower school performance in association with higher level of ST (Kantomaa et al., 2015).

This study focuses on comparing PA, sleep and ST between sport club participants and non-participants. Generally accepted recommendations under these topics are used as a reference. Individual sport participants are also compared with team sport participants.

\section{Methods}

This study is part of the Health Promotion Sports Club (HPSC) study conducted in Finland by the consortium of University of Jyväskylä, six sports \& exercise medicine centers (SMC) and UKK institute (Kokko et al., 2015). The sports club participants (SP) sample included a group of 15 year-olds $(n=759)$ in ten most popular sports in Finland (basketball, cross-country skiing, floor ball, soccer, gymnastics, ice-hockey, orienteering, skating, swimming, and track and field). Data was collected in the middle of the main competition season from January to May 2013 for winter sports, and from August to December 2013 for summer sports.

Sampling was carried out with probability proportional to size (PPS) method, applying regional stratification and clustering using sports club as primary sampling unit. The sports clubs located within the same regions as the SMC and with several clubbased background variables (geographical location, magnitude (larger and smaller), and area type (city versus countryside) standardized; generating the club sample nationally and sport-wide representative. In each sports club, five boys and five girls were targeted 
and youths were sampled using simple random sampling (SRS) from all of those fulfilling the age range. In total, 1889 SPs were invited to participate to an online survey and 759 responded (response rate $40.0 \%$ of sports participants).

The second sample was a group of similar aged secondary school adolescents. Sampling was carried out with probability proportional to size (PPS) method applying regional stratification and clustering using school as primary sampling unit. The sample size of the clubs was power calculated by Stata V.11.0 using data from Kokko (2010). Within schools one class was sampled using simple random sampling (SRS). In total, 2074 pupils were asked to participate in the study. In total, 1442 participants (response rate $69.5 \%$ ) from 100 secondary schools responded. The schools were collated from each district where SMC were located, including nearby rural areas. This group included non-sports club participants (NSP, $n=913$ ), as well as sports club participations (SP) $(n=529)$. These two data sets (school data and sport club data) were combined to. Duplicate SP entries were removed.

Health behaviors of adolescents were enquired with questionnaires including items concerning PA, sleep duration, and ST variables. Also, school performance and school aspirations were examined. Reliability and validity of self-reported screen time behavior has been assessed in many countries (Bucksch et al., 2016).

Self-reported MVPA was estimated by a questionnaire from the question: Consider your last seven days. Indicate in how many days have you been physically active at least for 60 minutes $(0 / 1 / 2 / 3 / 4 / 5 / 6 / 7)$ ? This question has been used widely e.g. in HBSC (Health Behavior in School-Aged Children) study (Currie et al., 2012). The intensity level (moderate to vigorous) was determined for the respondents prior to question with examples. For logistic regression analysis, this variable was dichotomized to daily (7) or not daily $(0-6)$.

The frequency of vigorous intensity physical activity (VPA) was estimated by a questionnaire from with the question: How often do you normally perform PA, which get out of breath or sweat (daily/4 - 6 times a week/2 - 3 times a week/once a week/once a month/less than once a month/never)? For logistic regression analysis, this variable was dichotomized to once to week or less and at least 2 - 3 times per week.

Adolescents sleep duration was asked what time they went to bed on weekdays (21:00/21:30/22:00 . . / /02:00 or later) and the time they got up (05:00/05:30/6:00/ ... / 10:00)? Sleeping time was estimated as the time interval between these figures. The same sleeping time was separately asked for weekends. Same questions were asked for weekends, but waking hour options were extended (...14:00 or later). Total sleep time was calculated both for weekdays and weekend days. This variable was dichotomized to meeting the recommendations for sleep i.e. less than nine hours and nine hours or more.

Self-reported ST was estimated from a questionnaire with the question: How many hours you regularly spend with following gadgets (television/videos or DVD/playing with computer or console games/computer or tablet/other use than games)? Total ST was the sum of before (morning) and after school hours ST variables. Reliability of 
self-reported screen time behavior has been assessed in many countries (Bucksch et al., 2016). This variable was dichotomized to those who met the recommendations $(<2$ hours) and those, who exceeded the recommendations ( $>2$ hours).

Since in earlier studies school performance has been noticed significant background variable for health behaviors of adolescents (Bradley \& Greene, 2013), it was taken into the analyses.

School performance was dissected by the mean score of all school marks (min. 4-max 10). Latest mean score of the school marks was asked in the questionnaire. Mean scores were categorized into three groups based on data; low $(<7.5)$, moderate $(7.5-8.4)$ and high (>8.4).

Future educational aspirations were asked by the question: "What do you think you will do after secondary school?" Response categories included; "Apply to high school"; "apply to vocational education"; "apply for an apprenticeship/training; go to work"; "become unemployed"; "do not know" There was a low number of responses corresponding to "Do not know $(n=6)$ " and "Become unemployed" $(n=91)$, and these were excluded from the analysis. The remaining categories were dichotomized by renaming the general upper secondary school alternative as "higher education", and combining the remaining alternatives as "vocational education or work".

Descriptive statistics included tests of differences in PA, sleep and ST between genders, SP and NSP. The pairwise associations between the variables were tested with Chi-squared tests. The significance level was $p<0.05$ in all statistical tests.

Multilevel logistic regression analyses were conducted to study the associations between participation in sports club activities and PA and sleep and ST. School and sports club membership were used as a second level nesting variable. Two-level models were conducted for all participants (school data and sports club data) and separately for sports club participants (sports club data only). For the separate SP model the upper level variance proved to be statistically insignificant and basic logistic regression was applied. Odds ratios (OR) were calculated with $95 \%$ confidence intervals (CI).

The study was carried out in conformance with the declaration of Helsinki. Ethical approval was granted for the study by Committee of Health Care, District of Central-Finland (record number: 23U/2012). After the permission was obtained, a written consent was obtained from the participants and all respondents were notified that they had the option to refuse to participate and withdraw from the study at any time (Kokko et al., 2015).

\section{Results}

A total of 211314 to 16 years old adolescents (boys $n=1030$, girls $n=1083$ ) participated in the study and 1200 (57.0\%) were sports club participants (SP) and 913 (43.0\%) non-participants (NP). From SPs $52.3 \%$ were boys and $47.7 \%$ girls. From NPs $44.0 \%$ were boys and $56.0 \%$ were girls (Table 1 ).

Totally, $11.8 \%$ of girls and $23.7 \%$ of boys met the guidelines for weekly MVPA. However, $83.7 \%$ of girls and $88.5 \%$ of boys met the guidelines for VPA (Table 1 ). The 
Table 1. Percentage of sports club participants (SPs) and non-participants (NPs) who meets the recommendations for daily MVPA, VPA, sleep and screen time (\%).

\begin{tabular}{|c|c|c|c|c|c|}
\hline & SP girls & NSP girls & SP boys & NSP boys & All \\
\hline \multicolumn{6}{|l|}{ MVPA (60 minutes in a day) } \\
\hline Daily & 17.5 & 5.5 & 30.3 & 13.4 & 17.6 \\
\hline 4 - 6 days/week & 64.0 & 35.0 & 58.1 & 39.4 & 50.0 \\
\hline 2 - 3 days/week & 15.8 & 44.8 & 10.8 & 34.1 & 24.8 \\
\hline Once a week or seldom & 2.8 & 14.7 & 2.7 & 13.2 & 7.7 \\
\hline \multicolumn{6}{|l|}{ VPA } \\
\hline Daily & 14.0 & 3.3 & 21.5 & 8.0 & 12.5 \\
\hline 4 - 6 times a week & 62.2 & 21.1 & 59.4 & 26.1 & 44.6 \\
\hline 2 - 3 times a week & 21.7 & 43.4 & 16.7 & 40.3 & 29.0 \\
\hline Once a week or seldom & 2.1 & 32.1 & 2.1 & 25.6 & 13.9 \\
\hline \multicolumn{6}{|l|}{ Sleep } \\
\hline$<8: 00$ hours schooldays & 21.7 & 29.9 & 18.7 & 32.7 & 24.9 \\
\hline 8:00 - 8:59 hours schooldays & 57.3 & 45.4 & 50.3 & 45.1 & 50.3 \\
\hline$\geq 9: 00$ hours schooldays & 21.0 & 24.7 & 30.0 & 22.2 & 24.8 \\
\hline$<9$ hours weekends & 5.5 & 13.7 & 6.0 & 20.6 & 10.5 \\
\hline$\geq 9$ hours weekends & 94.5 & 86.3 & 94.0 & 79.4 & 89.5 \\
\hline \multicolumn{6}{|l|}{ Screen time } \\
\hline$<2$ hours & 84.4 & 61.4 & 76.3 & 47.4 & 69.4 \\
\hline$\geq 2$ hours & 15.6 & 38.6 & 23.7 & 52.6 & 30.6 \\
\hline
\end{tabular}

latter quantity decreased to $51.8 \%$ for girls and $62.6 \%$ for boys when at least 4 times per week VPA was dissected. Among SPs, $17.5 \%$ of girls and $30.3 \%$ of boys met the MVPA guideline. Over third (36.0\%) of SPs had a total weekly PA over 14 hours, but they did not fulfill the recommendation because, they reported to do PA in 6 days (Table 1).

Average self-reported sleeping time in schooldays was 8:06 (SD 0:48) hours for girls and 8:12 (0:54) hours for boys. On weekend the average sleep time was 10:36 (1:36) hours for girls and 10:42 (1:42) for boys. The SPs reported going 9 minutes earlier to bed (22:45) than the NSPs $(22: 54$, respectively) $(P<0.001)$, but there were no differences in waking up time. SPs reported to sleep longer than NSPs during weekends by 1:15 hours $(p<0.001)$, but this difference did not occur during weekdays. From SPs $96.0 \%$ slept 11 hours or more in the weekend.

Daily mean ST was 1:36 (1:24) hours among girls and 2:00 (1:48) hours among boys $(p<0.001)$. Mean ST per day among SPs was 1:24 (1:18) hours and among NSPs 2:00 $(1: 42)$ hours $(p<0.001)$. SPs girls $(1: 06[0: 54]$ hours $)$ had less ST than SPs boys (1:36 [1:36] hours) $(P<0.001)$.

In the logistic regression analysis participation in sports clubs was associated positively with meeting the guidelines for MVPA and VPA, lower levels of ST and longer 
sleeping hours during weekends when compared to NSPs (Table 2). Those, who participated in sports club activities, reached the recommendations for MVPA more likely (OR 3.2, CI 2.4 - 4.3) as well as for VPA (OR 16.7, CI 10.9 - 25.9). Likewise, SPs were more likely to sleep at least 9 hours in weekends (OR 2.6, CI 1.8 - 3.6) and more likely to meet the recommendations for ST (OR 2.9, CI 2.3 - 3.6) (Table 2). Gender also associated with the MVPA, boys being more likely to achieve the recommendation for MVPA than girls (OR 2.2, CI 1.7 - 2.8). Also, better school performance associated with better sleep habits during the weekdays and lower daily ST. Those having best grades in the school were more likely to get recommended amount of sleep (OR 1.8, CI $1.2-2.6$ ) and more likely not to exceed the recommended ST (OR 4.1, CI 2.9 - 5.9) (Table 2).

\section{Discussion}

The purpose of this study was to compare PA, sleep duration and ST among Finnish sport club participants and non-participants. The results showed that boys were more physically active and had more ST than girls. Sport club participation associated positively with higher level of PA, less screen-time and longer sleep duration (in weekends) when compared with non-participants.

Sport club participants were more physically active than non-participants. Still, only $24.2 \%$ of SPs met the MVPA guideline (60 minutes daily). The major explanation for this low fulfillment of the guideline is that the recommendation is based on daily activity and in sports training day off for resting and recovery is universal. In this study $36.0 \%$ of SPs reported of having overall PA over 14 hours per week, but they were

Table 2. Logistic regression models for PA, sleep and screen time.

\begin{tabular}{|c|c|c|c|c|c|c|}
\hline & $\mathrm{n}(\%)$ & $\begin{array}{c}\text { OR for sleep } \\
\text { week }>9 \text { hours }\end{array}$ & $\begin{array}{c}\text { OR for sleep } \\
\text { weekend }>9 \text { hours }\end{array}$ & $\begin{array}{l}\text { OR for screen } \\
\text { time }<2 \text { hours }\end{array}$ & $\begin{array}{c}\text { OR for MVPA } 60 \\
\text { minutes/day }\end{array}$ & $\begin{array}{l}\text { OR for VPA } 2 \text { - } 3 \\
\text { times/week }\end{array}$ \\
\hline \multicolumn{7}{|l|}{ Gender } \\
\hline Girl & $1047(51)$ & 1 & 1 & 1 & 1 & 1 \\
\hline Boy & $1003(49)$ & $1.3(1.1-1.7)^{\star *}$ & $0.7(0.5-1.0)$ & $0.7(0.6-0.9)^{\star *}$ & $2.2(1.7-2.8)^{\star * \star}$ & $1.4(1.0-1.8)^{*}$ \\
\hline \multicolumn{7}{|l|}{ Educational aspirations } \\
\hline Vocational school/work & $704(34)$ & 1 & 1 & 1 & 1 & 1 \\
\hline Higher education & $1346(66)$ & $0.6(0.4-0.8)^{\star * *}$ & $1.4(1.0-2.1)$ & $1.00(0.7-1.2)$ & $1.1(0.7-1.5)$ & $1.0(0.8-1.5)$ \\
\hline \multicolumn{7}{|l|}{ Mean score of school report } \\
\hline$<7.4$ & $906(44)$ & 1 & 1 & 1 & 1 & 1 \\
\hline $7.5-8.4$ & $746(36)$ & $1.1(0.8-1.5)$ & $1.8(1.2-2.5)^{\star}$ & $1.5(1.1-2.0)^{\star \star}$ & $1.0(0.7-1.4)$ & $1.1(0.8-1.5)$ \\
\hline$>8.5$ & $398(20)$ & $1.8(1.2-2.6)^{\star *}$ & $1.4(0.8-2.2)$ & $4.1(2.9-5.9)^{\star \star \star}$ & $1.0(0.6-1.5)$ & $1.8(1.2-2.6)^{\star \star}$ \\
\hline \multicolumn{7}{|l|}{$\begin{array}{c}\text { Participation in sports club } \\
\text { activities }\end{array}$} \\
\hline No & $852(42)$ & 1 & 1 & 1 & 1 & 1 \\
\hline Yes & $1198(58)$ & $1.2(0.9-1.4)$ & $2.6(1.8-3.6)^{\star \star \star}$ & $2.9(2.3-3.6)^{\star \star \star}$ & $3.2(2.4-4.3)^{\star \star \star}$ & $16.7(10.9-25.9)^{\star \star \star}$ \\
\hline
\end{tabular}

Note: ${ }^{*}=p=0.05,{ }^{* *}=p=0.01,{ }^{* *}=p<0.01$. 
physically active in six days. Hence, it is essential to consider whether PA recommendations are unsuitable for young athletes or whether there is a need for athlete-specific recommendations e.g. daily based recommendation should not be the only variable to measure adequate PA for young athletes.

As it has been found in earlier studies, participation in sports and more generally PA, have both positive and negative health indicators (Iannotti et al., 2009). In this study, participation in sports club activities associated with longer sleep duration in weekends, but no differences were reported during weekdays. On the other hand, SPs went to bed earlier than NPs in schooldays. However, even though there were more positive sleeping patterns during weekends, this may be because of shorter sleeps during school week. It may also be that SPs need to recover from their sport activities and hence they are sleeping longer during weekends.

From SPs, only $4.0 \%$ slept less than 11 hours on the weekend, which is two hours more than recommended sleep duration (National Sleep Foundation, 2006). Even though SPs had better sleep patterns during weekends, it may be also reasonable to question the overall sleeping habits. Especially irregular sleeping habits between schooldays and weekends may be harmful (Crowley, Acebo, \& Caeskadon, 2007), because it has been recommended, that sleep time should not vary more than one hour between days. Also, more than 11 hours of sleep is not recommended (Hirshkowitz, et al., 2015).

SPs reported less ST. SPs spent time in the sports club activities, but also transportation to organized sport may diminish ST. In addition, they may spend more time in free play with friends, outside of organized sport. There are proofs of negative association of the distance of sporting facilities and PA (Limstrand, 2008).

It has been shown that school performance is associated with substance use. In this study it was found that there is an association with school performance and health habits. Good school marks associated with lower ST and longer sleep duration during school week. Also, high school as a future school aspiration was associated with longer sleeping patterns during week. In previous research has shown that good sleeping habits are in association with better school performance (Trockel, Barnes, \& Ennis, 2000).

Future research could be directed either for younger and older age groups. Also, doing longitudinal research or for follow-up of participants in this study could be a potential area for study in the future. This kind of research could give more information on how health habits develop in the adolescence and how participation or drop-out in sports influence to the health habits of adolescents, for example, does sport participation have broader health promotion effects? Future research could profound the understanding of health habits of participants in different sports. Also, other health habits than studied here (PA, ST and sleep) could be targeted.

This study included participants aged 14 - 16. In the self-reported questionnaire, there is always a possibility for bias. Participants may underrate or overrate their levels of PA, sleep or ST, for example without diary entry, evaluation of ST with different devices may be very difficult. Also, it is very easy to forget all ST during the day. Some of 
the participants may not notice the use of smart phone as a ST. However, there are long-term data from self-reported questionnaires and e.g. in Finland HBSC study has been implemented since 1984 (Trost, 2007). Nowadays, there are numerous devices (e.g. accelerometer), which can measure also ST. In the future, research objective measurements should be used to evaluate both PA and ST to get more accurate results.

\section{Conclusion}

This study contributes several proposals for action. To reach their athletic goals, Finnish sports club participants should increase their overall PA. At the moment, the majority of SPs do not meet the PA recommendations for (health). However, it should be noted that the current daily claim of the PA recommendations may be inadequate for young athletes. The majority of adolescents-both SPs and NPs-did not sleep enough to reach the recommendation. The importance of adequate sleep for performance and recovery should be emphasized for young athletes. Also, due to wide difference in sleep duration between weekdays and weekends SPs should be more aware of the importance for regular sleep times. Better sleeping habits could not only give better performance in sports, but also in school for these young sport participants. Even though the ST among young SPs is not that high as it is among NP counterparts, this topic should be also underlined for young athletes. These topics should be clarified and included in coach training and hence, enhance sports clubs and coaches' health promotion activity.

\section{Acknowledgements}

This work was supported by Ministry of Education and Culture (major, grant number: 6/091/2011), Ministry of Social Affairs and Health (minor, grant number: 152/THL/TE/ 2012).

\section{References}

Aira, T., Kannas, L., Tynjälä, J., Villberg, J., \& Kokko, S. (2013). Hiipuva liikunta nuoruusiässä. Drop off-ilmiön aikatrendejä ja kansainvälistä vertailua WHO-koululaistutkimuksen (HBSCStudy) aineistolla 1986-2010. [Diminishing Physical Activity in Adolescence. The Time Trends and International Comparisons of the Drop-Off Phenomena in the 1986-2010 Data of Health Behavior in School-Aged Children Study]. Jyväskylä: Publications of Research Center for Health Promotion at University of Jyväskylä 5.

Borraccino, A., Lemma, P., Iannotti, R.J., Zambo, A., Dalmasso, P., \& Cavallo, F. (2009). Socioeconomic Effects on Meeting Physical Activity Guidelines: Comparisons among 32 Countries. Medicine and Science in Sports and Exercise, 41, 749-756. http://dx.doi.org/10.1249/MSS.0b013e3181917722

Bradley, B. J., \& Greene, A. C. (2013). Do Health and Education Agencies in the United States Share Responsibility for Academic Achievement and Health? A Review of 25 Years of Evidence about the Relationship of Adolescents' Academic Achievement and Health Behaviors. Journal of Adolescence Health, 52, 523-532. http://dx.doi.org/10.1016/j.jadohealth.2013.01.008

Brand, S., Gerber, M., Beck, J., Hatzinger, M., Pühse, U., \& Holsboer-Trachsler, E. (2010). High Exercise Levels Are Related to Favorable Sleep Patterns and Psychological Functioning in Adolescents: A Comparison of Athletes and Controls. Journal of Adolescence Health, 46, 133- 


\section{1. http://dx.doi.org/10.1016/j.jadohealth.2009.06.018}

Bucksch, J., Sigmundova, D., Hamrik, Z., Troped, P. J., Melkevik, O., Ahluwalia, N., \& Inchley, J. (2016). International Trends in Adolescent Screen-Time Behaviors from 2002 to 2010. Journal of Adolescents Health, 58, 417-425. http://dx.doi.org/10.1016/j.jadohealth.2015.11.014

Crowley, S. J., Acebo, C., \& Caeskadon, M. A. (2007). Sleep, Circadian Rhythms, and Delayed Phase in Adolescence. Sleep Medicine, 8, 602-612. http://dx.doi.org/10.1016/j.sleep.2006.12.002

Currie, C., Zanotti, C., Morgan, A., Currie, D., de Looze, M., Roberts, C., Samdal, O., Smith, O. R. F., \& Barnekow V. (2012). Social Determinants of Health and Well-Being among Young People. Copenhagen: World Health Organization Regional Office for Europe.

Garaulet, M., Ortega, F. B., Ruiz, J. R., Rey-López, J. P., Béghin, L., Manios, Y., Cuenca-García, M., \& Moreno, L. A. (2011). Short Sleep Duration Is Associated with Increased Obesity Markers in European Adolescents: Effect of Physical Activity and Dietary Habits. The Helena. International Journal of Obesity, 35, 1308-1317. http://dx.doi.org/10.1038/ijo.2011.149

Gråsten, A., Liukkonen, J., Jaakkola, T., \& Tammelin, T. (2014). Finnish Report Card 2014 on Physical Activity for Children and Youth. Jyväskylä: Jyväskylä Printing House.

Hakkarainen, H., Härkönen, A., Niemi-Nikkola, K., Mäenpää, P., Potinkara, P., Kujala, A., Jaakkola, T. \& Kantosalo, K. (2008). Urheilevien lasten ja nuorten fyysis-motorinen harjoittelu. Selvitysraportti. [Report on Physiological and Motor Training of Sporting Children and Adolescents]. Helsinki: SLU-Paino.

Hirshkowitz, M., Whiton, K., Albert, S., Alessi, C., Bruni, O., DonCarlos, L., Hazen, N., \& Hillard, P. J. A. (2015). National Sleep Foundation's Sleep Time Duration Recommendations: Methodology and Results Summary. Sleep Health, 1, 40-43.

http://dx.doi.org/10.1016/j.sleh.2014.12.010

Iannotti, R. J., Kogan, M. D., Janssen, I., \& Boyce, W. F. (2009). Patterns of Adolescent Physical Activity, Screen-Based Media Use, and Positive and Negative Health Indicators in the US and Canada. Journal of Adolescence Health, 44, 493-499.

http://dx.doi.org/10.1016/j.jadohealth.2008.10.142

Kalman, M., Inchley, J., Sigmundova, D., Iannotti, R. J., Tynjälä, J. A., Hamrik, Z., Haug, E., \& Bucksch, J. (2015). Secular Trends in Moderate-to-Vigorous Physical Activity in 32 Countries from 2002 to 2010: A Cross-National Perspective. European Journal of Public Health, 25, 3740. http://dx.doi.org/10.1093/eurpub/ckv024

Kantomaa, M. T., Stamatakis, E., Kankaanpää, A., Kajantie, A., Laanila, E., \& Tammelin, T. (2015). Associations of Physical Activity and Sedentary Behavior with Adolescent Academic Achievement. Journal of Research on Adolescence. http://dx.doi.org/10.1111/jora.12203

Karaca, A., Caglar, E., Bilgilli, N., \& Ayez, S. (2011). Screen Time of Adolescents in an Economically Developing Country: The Case of Turkey. Annals of Human Biology, 38, 28-33. http://dx.doi.org/10.3109/03014460.2010.486383

Kin-Isler, A., Asci, F. H., Altintas, A., \& Guven-Karahan, B. (2009). Physical Activity Levels and Patterns of 11 - 14 Year-Old Turkish Adolescents. Adolescence, 44, 1005-1015.

Kokko, S. (2010). Health Promoting Sports Club-Youth Sports Clubs' Health Promotion Profiles, Guidance, and Associated Coaching Practice, in Finland. In Studies in Sport, Physical Activity and Health 144. Jyväskylä: University of Jyväskylä.

Kokko, S., Selänne, H., Alanko, L., Heinonen, O. J., Korpelainen, R., Savonen, K., Vasankari, T., \& Parkkari, J. (2015). Health Promotion Activities of Sports Clubs and Coaches and Health and Health Behaviours in Young Participating in Sports Clubs Compared to Non-Participants: The Health Promoting Sports Club (HPSC) Study. BMJ Open Sport \& Exercise Medicine, 1, e000034. http://dx.doi.org/10.1136/bmjsem-2015-000034 
Limstrand, T. (2008). Environmental Characteristics Relevant to Young People's Use of Sport Facilities: A Review. Scandinavian Journal of Medicine \& Science in Sports, 18, 275-287.

http://dx.doi.org/10.1111/j.1600-0838.2007.00742.x

National Sleep Foundation (2006). Sleep in America Poll. Washington DC: National Sleep Foundation.

Nuutinen, T., Roos, E., Ray, C., Villberg, J., Välimaa, R., Rasmussen, M. et al. (2014). Computer Use, Sleep Duration and Health Symptoms: A Cross-Sectional Study of 15-Year Olds in Three Countries. International Journal of Public Health, 59, 619-628. http://dx.doi.org/10.1007/s00038-014-0561-y

Page, A. S., Cooper, A. R., Griew, P., \& Jago, R. (2010). Children's Screen Viewing Is Related to Psychological Difficulties Irrespective of Physical Difficulties Irrespective of Physical Activity. Pediatrics, 126, e1011-e1017. http://dx.doi.org/10.1542/peds.2010-1154

Pyky, R., Jauho, A. M., Ahola, R., Ikäheimo, T. M., Koivumaa-Honkanen, H., Mäntysaari, M. et al. (2015). Profiles of Sedentary and Non-Sedentary Young Men-A Population-Based MOPO Study. BMC Public Health, 15, 1164. http://dx.doi.org/10.1186/s12889-015-2495-6

Silva, G., Andersen, L. B., Aires, L., Mota, J., Oliveira, J., \& Ribeiro, J. C. (2013). Associations between Sports Participation, Levels of Moderate to Vigorous Physical Activity and Cardiorespiratory Fitness in Children and Adolescents. Journal of Sports Science, 31, 1359-1367. http://dx.doi.org/10.1080/02640414.2013.781666

Singh, M., \& Baig, M. M. (2014). A Comparative Study on Effects of Sleeping Habits on College Student Athletes and Non-Athletes. European Academic Research, 2, 2866-2878.

Sirard, J. R., Pfeiffer, K. A., Dowda, M., \& Pate, R. R. (2008). Race Differences in Activity, Fitness, and BMI in Female Eighth Graders Categorized by Sports Participation Status. Pediatric Exercise Science, 20, 198-210. http://dx.doi.org/10.1123/pes.20.2.198

Strasburger, V., \& Hogan, M. (2013). Policy Statement: Children, Adolescent, and the Media. Pediatrics, 132, 958-961. http://dx.doi.org/10.1542/peds.2013-2656

Taliaferro, L. A., Rienzo, B. A., \& Donovan, K. A. (2010). Relationships between Youth Sport Participation and Selected Health Risk Behaviors from 1999 to 2007. Journal of School Health, 80, 399-410. http://dx.doi.org/10.1111/j.1746-1561.2010.00520.x

Thibault, H., Contrand, B., Saubusse, E., Baine, M., \& Maurice-Tison, S. (2010). Risk Factors for Overweight and Obesity in French Adolescents: Physical Activity, Sedentary Behavior and Parental Characteristics. Nutrition, 26, 192-200. http://dx.doi.org/10.1016/j.nut.2009.03.015

Trockel, M. T., Barnes, M. D., \& Ennis, D. L. (2000). Health-Related Variables and Academic Performance among First-Year College Students: Implications for Sleep and Other Behaviors. Journal of American College Health, 49, 125-131. http://dx.doi.org/10.1080/07448480009596294

Trost, S. G. (2007). State of the Art Reviews: Measurement of Physical Activity in Children and Adolescents. American Journal of Lifestyle Medicine, 1, 299-314. http://dx.doi.org/10.1177/1559827607301686

Tynjälä, J., Kannas, L., Levälahti, E., \& Välimaa, R. (1999). Perceived Sleep Quality and Its Precursors in Adolescents. Health Promotion International, 14, 155-166. http://dx.doi.org/10.1093/heapro/14.2.155

WHO (2013). Global Recommendations on Physical Activity for Health. Geneva: World Health Organization. 
Submit or recommend next manuscript to SCIRP and we will provide best service for you:

Accepting pre-submission inquiries through Email, Facebook, LinkedIn, Twitter, etc. A wide selection of journals (inclusive of 9 subjects, more than 200 journals)

Providing 24-hour high-quality service

User-friendly online submission system

Fair and swift peer-review system

Efficient typesetting and proofreading procedure

Display of the result of downloads and visits, as well as the number of cited articles

Maximum dissemination of your research work

Submit your manuscript at: http://papersubmission.scirp.org/

Or contact ape@scirp.org 